\title{
Monitoring Hemolysis with a Parallel Plate Capacitor ${ }^{\dagger}$
}

\author{
Anays Acevedo-Barrera ${ }^{1}$, Doris Atenea Cerecedo-Mercado ${ }^{2}$ and Augusto García-Valenzuela 1,* \\ 1 Centro de Ciencia Aplicadas y Desarrollo Tecnológico, Universidad Nacional Autónoma de México, \\ Apartado Postal 70-186, Ciudad de México 04510, Mexico; aacevedo900510@gmail.com \\ 2 Laboratorio de Hematobiología, Escuela Nacional de Medicina y Homeopatía, Instituto Politécnico \\ Nacional, Guillermo Massieu Helguera no. 239, La Escalera Ticomán, Ciudad de México 07320, Mexico; \\ dcereced@prodigy.net.mx \\ * Correspondence: augusto.garcia@ccadet.unam.mx \\ + Presented at the 5th International Symposium on Sensor Science (I3S 2017), Barcelona, Spain, \\ 27-29 September 2017.
}

Published: 4 December 2017

A parallel plate capacitor can be used as a high resolution sensor of the electrical characteristics of a liquid sample contained by the capacitor. We are interested specifically in using parallel plate capacitors to characterize and monitor processes in biofluids. In this case, only dynamic measurements of the capacitance and resistance at a fixed frequency are generally convenient. In biofluids, the high polarizability of water and the electrical conduction by ions in solution, determine the electrical response of the system. When there are biological cells in suspension, the ion density is, in general, different inside the cell than outside it. Then, cells may act as strong polarizable entities, through the so-called Maxwell-Wagner effect. In addition, the formation of an electrical double layer at the interfaces between the biological fluid and the electrodes can influence both, the capacitance and resistance of the system. All these electrical effects combined must be taken into account to interpret measurements of the equivalent capacitance and resistance at a given frequency of the system. In this work, we combine all the mentioned effects into a practical model appropriate for frequencies above $10 \mathrm{kHz}$. Then, we present results of monitoring the process of hemolysis in human blood samples exposed to different values of osmotic stress. We use the model to interpret the obtained results. Overall, our conclusion is that electrical-impedance monitoring of a parallel plate capacitor containing blood is in fact sensitive to the hemolysis process and, more generally, can be a competitive way to characterize the osmotic fragility of biological cells. We discuss how to optimize measurements for future development of ad hoc sensors.

(C) 2017 by the authors. Licensee MDPI, Basel, Switzerland. This article is an open access article distributed under the terms and conditions of the Creative Commons Attribution (CC BY) license (http://creativecommons.org/licenses/by/4.0/). 